\title{
CONF-9609212--3 SAND--960-2151C PARAMETRIC STUDY ON THE SOLDERABILITY OF ETCHED PWB COPPER
}

\author{
F. M. Hosking, J. O. Stevenson, and C. L. Hernandez \\ Sandia National Laboratories \\ Albuquerque, NM
}

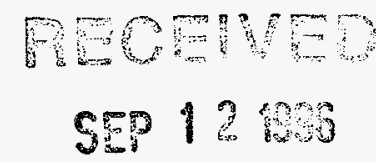

\begin{abstract}
The rapid advancement of interconnect technology has resulted in a more "engineered" approach to designing and fabricating printed wiring board (PWB) surface features. Recent research at Sandia National Laboratories has demonstrated the importance of surface roughness on solder flow. This paper describes how chemical etching was used to enhance the solderability of surfaces that were normally difficult to wet. The effects of circuit geometry, etch concentration, and etching time on solder flow are discussed. Surface roughness and solder flow data are presented. The results clearly demonstrate the importance of surface roughness on the solderability of fine PWB surface mount features. ${ }^{*}$
\end{abstract}

\section{KEYWORDS:}

Surface Roughness, Chemical Etching, Solder Flow

\section{INTRODUCTION}

Fluid flow on rough surfaces has been extensively studied for many years [1-9]. Early work by Wenzel described the conditions necessary for surface wetting to occur [1]. He developed a relationship showing that increases in roughness produced smaller contact angles between a liquid and a solid surface. This relationship has been subsequently investigated by other researchers to better understand the wetting behavior of solder on rough surfaces. Romero \& Yost [8] and Yost et al [9] recently identified an additional driving force for wetting, namely, flow along open channel capillaries. Solder flow along Vshaped grooves was found to depend on the orientation and physical dimensions of the grooves.

Copper surface finishes, common to most printed wiring boards (PWBs), inherently possess some degree of open capillary roughness that affects solderability. Additional surface roughening can be achieved through selective mechanical or chemical processing. The resulting surface offers an opportunity for improved manufacturability of solder interconnects on electronic assemblies.

The rapid advancement of interconnect technology has provided the impetus for developing a more "engineered" approach toward enhancing PWB solderability. As fine pitch technology becomes the norm in circuit designs, better control of solder delivery to critical surface features will be necessary to assure the formation of reliable joints. The effort to maximize PWB real estate, by increasing circuit density through ever finer pitch size, will certainly

\footnotetext{
* This work was performed at Sandia National Laboratories, which is supported by the U.S. Department of Energy under contract number DE-AC04-94AL 85000, in collaboration with the National Center for Manufacturing Sciences.
}

cause additional solderability problets, sines potentially larger relative percentage of unwetted surface area can result.

The thinning of solder coatings around convex points, particularly at the barrel opening of a PWB plated through hole (PTH), often results in limited solder flow onto the topside land. This phenomenon is commonly referred to as a "weak-knee" and can be observed during typical PWB fabrication and circuit assembly. Solder joints at the "weak-knee" are often poor and can consequently fail prematurely. Chemical etching was recently demonstrated as a solution to this solder flow problem by roughening the barrel edge and enhancing solder flow [10].

There are numerous chemical and mechanical methods, therefore, that can produce the kind of surface features which promote solder wettability. For example, copper electroplating parameters can be adjusted to optimize roughness profiles with improved solderability [9]. Chemical etching can yield similar results [11, 12].

A variety of chemical solutions have been formulated to etch copper [10-16]. Typical uses include metal finishing, the manufacture of semiconductor devices, and the fabrication and assembly of printed circuit boards. A chemically etched surface, however, does not necessarily guarantee good solder wetting behavior, since deposited residues could inhibit flow and must usually be removed prior to solder processing.

This paper describes work recently conducted by Sandia National Laboratories, in collaboration with the National Center for Manufacturing Sciences' PWB Interconnect Systems Surface Finishes project, which characterized the effects of surface roughness on solder flow. The investigation demonstrated the importance of "engineering" the surface topography of fine lines and controlling the baseline surface conditions.

\section{MATERIALS \& EXPERIMENTAL PROCEDURE} A $10 \% \mathrm{HCl}$ baseline pretreatment and two chloride-based etching solutions were selected for the copper roughening study (Table 1). Ferric or cupric chloride $\left(\mathrm{FeCl}_{3}\right.$ or $\mathrm{CuCl}_{2}$ ) were the basis for the etchant formulations. Hydrogen peroxide $\left(\mathrm{H}_{2} \mathrm{O}_{2}\right)$ was added to the $\mathrm{CuCl}_{2}$ solutions to accentuate the etch process. The peroxide is an oxidizer and promotes preferential etching by the $\mathrm{CuCl}_{2}$ through an iterative reoxidation and etch process. A third etching procedure used a sequential $\mathrm{CuCl}_{2}$ and $\mathrm{FeCl}_{3}$ dual etch.

Preliminary etching experiments were conducted with an etch time of 60 seconds. Subsequent etch times were varied from 30 to 120 seconds. Different $\mathrm{FeCl}_{3}$ and $\mathrm{CuCl}_{2}$ 


\section{DISCLAIMER}

Portions of this document may be illegible in electronic image products. Images are produced from the best available original document. 


\section{DISCLAIMER}

This report was prepared as an account of work sponsored by an agency of the United States Government. Neither the United States Government nor any agency thereof, nor any of their employees, makes any warranty, express or implied, or assumes any legal liability or responsibility for the accuracy, completeness, or usefulness of any information, apparatus, product, or process disclosed, or represents that its use would not infringe privately owned rights. Reference berein to any specific commercial product, process, or service by trade name, trademark, manufacturer, or otherwise does not necessarily constitute or imply its endorsement, recommendation, or favoring by the United States Government or any agency thereof. The views and opinions of authors expressed herein do not necessarily state or reflect those of the United States Government or any agency thereof. 
concentrations $(127,253$, and $380 \mathrm{~g})$ were investigated. Corresponding $\mathrm{H}_{2} \mathrm{O}_{2}$ concentrations in the $\mathrm{CuCl}_{2}$ solutions were 7, 14, and $21 \mathrm{ml}$. Samples were rinsed in ethanol and deionized water before being immersed in the etchant baths. Etched samples were given a final rinse in dilute $\mathrm{HCl}$ and deionized water.

Table 1: Surface Treatments of PWB Copper Samples

1. $10 \% \mathrm{HCl}$ baseline pretreatment, with solvent clean.

2. $\mathrm{CuCl}_{2} / \mathrm{H}_{2} \mathrm{O}_{2} / \mathrm{HCl}(50$ vol. $\% \mathrm{HCl}$ stock solution with 7-21 $\mathrm{ml} \mathrm{H}_{2} \mathrm{O}_{2}$ and $127-380 \mathrm{~g} \mathrm{CuCl}_{2}$ per liter of stock solution).

3. $\mathrm{FeCl}_{3} / \mathrm{HCl}$ ( 50 vol. \% $\mathrm{HCl}$ stock solution with 127 $380 \mathrm{~g} \mathrm{FeCl}_{3}$ per liter of stock solution).

4. $\mathrm{CuCl}_{2} / \mathrm{H}_{2} \mathrm{O}_{2} / \mathrm{HCl}(50$ vol. $\% \mathrm{HCl}$ stock solution with $14 \mathrm{ml} \mathrm{H} \mathrm{O}_{2}$ and $253 \mathrm{~g} \mathrm{CuCl}_{2}$ per liter of stock solution) for $30 \mathrm{~s}$, followed by $\mathrm{FeCl} / \mathrm{HCl}(50 \mathrm{vol}$. \% $\mathrm{HCl}$ stock solution with $253 \mathrm{~g} \mathrm{FeCl}_{3}$ per liter of stock solution) for $30 \mathrm{~s}$.

Surface profilometry was used to measure the relative roughness of the etched surfaces and map their topography. The instrument, manufactured by WYKO Corporation, uses a white light interferometer source to measure the degree of fringe modulation or coherence. The system is capable of profiling surfaces with rootmean-square roughness ranging from $1 \AA$ to over $20 \mu \mathrm{m}$ and with steps over $100 \mu \mathrm{m}$. Surface area, arithmetic average, root-mean-square, and maximum peak-to-valley roughness measurements are typical outputs available with this technology. ASME 846.1 describes quantitative parameters used to characterize surfaces from measured profiles [17]. Parameters are typically profile-amplitude sensitive, profile-wavelength sensitive, or sensitive to both amplitude and wavelength.

Roughness measurements were performed initially on samples sectioned from a copper-clad, FR-4 panel to calibrate the test instrument. Baseline measurements were then made on the as-received test coupons before conducting the etching experiments. Similar measurements were performed after etching. The measurement area was approximately $58 \mu \mathrm{m} \times 77 \mu \mathrm{m}$.

The solder flow test vehicle (TV) was fabricated with conventional PWB materials and based on a layout design consisting of $0.006^{\prime \prime}(0.15 \mathrm{~mm})$ copper lines attached to individual outer $0.016^{\prime \prime}(0.4 \mathrm{~mm})$ diameter copper pads (Fig. 1). The substrate was a single-sided, $0.060^{\prime \prime}(1.52$ $\mathrm{mm}$ ) thick, epoxy resin/fiberglass-reinforced laminate (FR-4) board. Copper patterns were imaged and etched to represent a mini ball grid array (BGA) footprint. The nominal $\mathrm{Cu}$ thickness was $17 \mu \mathrm{m}(0.5 \mathrm{oz} . \mathrm{Cu})$.

The line and pad dimensions were based on a relationship developed for surface capillary flow of solder on a PWB surface [18]. Common to the line-pad geometry is the relationship between the line width, $\delta$, and pad radius, $r_{c}$. Solder flow onto a line from a pad was found to depend on certain values of the ratio $\delta$ to $r_{c}$. These geometric limits generally represent typical solder flow conditions observed during PWB assembly, where solder is either moved or contained along conductor paths. When $\delta / r_{c}$ is less than 0.5 , liquid solder normally does not readily flow from a pad onto an attached line. When $\delta / r_{c}$ exceeds 0.5 and sufficient solder is present, the probability of flow onto the line significantly improves. Since experimental results suggested favorable conditions for solder flow with a $0.75 \delta / r_{c}$ ratio, the BGATV line-pad dimensions were scaled to the 0.75 value. Even with this "ideal" geometric relationship, the effects of an increased edgeto-surface area ratio, greater variability in solder volume control on the smaller circuit, and inherent fabrication differences caused by sizing could influence actual wetting behavior. Considering these factors, surface topography should have a measurable effect on solder flow.

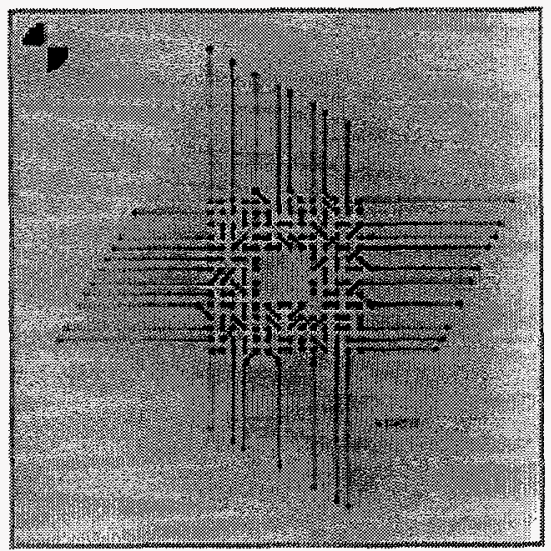

Figure 1: Ball Grid Array Test Vehicle (BGATV)

Solder paste was used in the study. The paste consisted of $85 \%$ eutectic $63 \mathrm{Sn} 37 \mathrm{~Pb}$ (wt. \%) metal powder with a rosin mildly activated (RMA) flux vehicle. A 0.012 " (0.3 mm) thick stencil was used to screen paste onto the outer pad surfaces. Additional RMA flux, containing 25\% solids in an alcohol carrier, was lightly applied to the exposed copper traces to facilitate flow once solder wetted each line. The BGATV was processed through a tabletop solder reflow machine. The unit has four conduction heat zones that were set at 90,140,240, and $100^{\circ} \mathrm{C}$. The sample transport bar speed was $9 \mathrm{in} / \mathrm{min}(3.8$ $\mathrm{mm} / \mathrm{s}$ ). The thermal profile yielded a ramp rate of approximately $1.5^{\circ} \mathrm{C} / \mathrm{s}$ and a $210-215^{\circ} \mathrm{C}$ peak temperature on the sample topside. The time spent above the solder melting temperature was typically $30-40 \mathrm{~s}$. The heat zones were fully inerted with technical grade nitrogen flowing at a rate of $30 \mathrm{SCFH}$. Flux residues were removed ultrasonically in trichloroethylene and rinsed in isopropyl alcohol after each test. 
Table 2: Optical Profilometry Measurements on Baseline and Etched BGATV Surfaces

Surface Treatment \& Time

Baseline, $10 \% \mathrm{HCl}$

$\mathrm{FeCl}_{3}(127 \mathrm{~g})^{*}, 30 \mathrm{~s}$

$\mathrm{FeCl}_{3}(127 \mathrm{~g})^{*}, 120 \mathrm{~s}$

$\mathrm{FeCl}_{3}(253 \mathrm{~g})^{*}, 75 \mathrm{~s}$

$\mathrm{FeCl}_{3}(380 \mathrm{~g})^{*}, 30 \mathrm{~s}$

$\mathrm{FeCl}_{3}(380 \mathrm{~g})^{*}, 120 \mathrm{~s}$

$\mathrm{CuCl}_{2}(127 \mathrm{~g})+\mathrm{H}_{2} \mathrm{O}_{2}(7 \mathrm{ml})^{*}, 30 \mathrm{~s}$

$\mathrm{CuCl}_{2}(127 \mathrm{~g})+\mathrm{H}_{2} \mathrm{O}_{2}(7 \mathrm{ml})^{*}, 120 \mathrm{~s}$

$\mathrm{CuCl}_{2}(253 \mathrm{~g})+\mathrm{H}_{2} \mathrm{O}_{2}(14 \mathrm{ml})^{*}, 75 \mathrm{~s}$

$\mathrm{CuCl}_{2}(380 \mathrm{~g})+\mathrm{H}_{2} \mathrm{O}_{2}(21 \mathrm{ml})^{*}, 30 \mathrm{~s}$

$\mathrm{CuCl}_{2}(380 \mathrm{~g})+\mathrm{H}_{2} \mathrm{O}_{2}(21 \mathrm{ml})^{*}, 120 \mathrm{~s}$

$\mathrm{CuCl}_{2}(253 \mathrm{~g})+\mathrm{H}_{2} \mathrm{O}_{2}(14 \mathrm{ml}) *, 30 \mathrm{~s}$

followed by $\mathrm{FeCl}_{3}(253 \mathrm{~g})^{*}, 30 \mathrm{~s}$

* (per liter of 50 vol. \% HCl stock solution)

$\begin{array}{clll}\begin{array}{c}\text { Area Path Index } \\ \underline{\mathrm{R}_{\mathrm{B}_{2}}\left(\mu \mathrm{m}^{2} / \mu \mathrm{m}^{2}\right)}\end{array} & \begin{array}{l}\text { Peak-to-Valley } \\ \mathrm{R}_{\mathrm{I}_{2}(\mu \mathrm{m})}\end{array} & \begin{array}{c}\mathrm{RMS} \\ \mathrm{R}_{\mathrm{Q}}(\mathrm{nm})\end{array} & \begin{array}{c}\text { Arithmetic Mean } \\ \underline{\mathrm{R}_{\mathrm{A}}(\mathrm{nm})}\end{array} \\ 1.768 \pm 0.102 & 4.6 \pm 0.2 & 405.1 \pm 21.8 & 311.6 \pm 16.9 \\ & & & \\ 2.453 \pm 0.053 & 7.1 \pm 1.5 & 727.0 \pm 214.4 & 553.6 \pm 183.1 \\ 3.101 \pm 0.201 & 10.0 \pm 1.5 & 1073.3 \pm 319.6 & 806.6 \pm 255.3 \\ 2.564 \pm 0.039 & 7.7 \pm 2.0 & 673.6 \pm 140.6 & 508.4 \pm 88.1 \\ 2.375 \pm 0.197 & 5.7 \pm 1.1 & 555.6 \pm 37.7 & 435.4 \pm 27.5 \\ 2.541 \pm 0.071 & 7.8 \pm 0.7 & 842.5 \pm 164.5 & 666.3 \pm 131.9 \\ & & & \\ 2.486 \pm 0.166 & 7.7 \pm 1.1 & 752.8 \pm 209.7 & 556.0 \pm 108.2 \\ 2.657 \pm 0.064 & 9.1 \pm 2.2 & 787.0 \pm 60.6 & 602.9 \pm 37.8 \\ 2.518 \pm 0.073 & 5.4 \pm 0.8 & 606.1 \pm 114.2 & 479.3 \pm 98.9 \\ 1.783 \pm 0.299 & 5.2 \pm 0.8 & 475.8 \pm 142.3 & 368.4 \pm 130.9 \\ 2.155 \pm 0.275 & 5.6 \pm 0.7 & 591.1 \pm 156.6 & 455.3 \pm 127.8 \\ 3.062 \pm 0.113 & 9.8 \pm 2.9 & 1207.7 \pm 248.6 & 930.7 \pm 197.4\end{array}$

\section{RESULTS AND DISCUSSION}

Optical profilometry results for the BGATV copper samples are presented in Table 2. Area path $\left(R_{p}\right)$, maximum peak-to-valley $\left(R_{T}\right)$, root-mean-square (rms, $R_{Q}$ ), and arithmetic mean $\left(R_{A}\right)$ roughness values were calculated from each measured profile. Since it was difficult to conclusively interpret peak-to-valley metrics due to the somewhat rippled surface produced by the underlying FR-4 laminate layers, experimental analysis was concentrated on the normalized surface area metric, $\mathrm{R}_{\mathrm{p}}$, although the other roughness parameters exhibited similar measured trends.

$R_{P}$ is determined by dividing the measured surface area by the projected measurement area. It generally does a good job in reflecting the roughness ratio in Wenzel's equation, which depends on the mean square slope of a surface, rather than its amplitude [9]. While $R_{P}$ is not mean square slope, the two metrics convey similar information. This normalized parameter is consequently more characteristic of general surface roughness, as compared to the localized nature of the other roughness parameters. The $R_{p}$ results are summarized in Fig. 2.

The $\mathrm{FeCl} / \mathrm{HCl}$ etch produced the largest roughness gains on the BGATV copper surfaces. The average roughness increase ranged between 35 and $75 \%$ of the baseline value. It should be noted that the baseline condition also exhibited a certain degree of roughness, as indicated by an area path roughness index of 1.768 . The lower concentration $\mathrm{FeCl}_{3}$ solution, with an etch time of $120 \mathrm{~s}$, yielded the roughest surface of the single etch experiments $\left(R_{p}=3.101\right)$. The higher concentration solutions did not necessarily produce the roughest surface.
Metallographic analysis suggested that the thin copper finish was self-limiting in achieving maximum roughness. As the more aggressive etch conditions dissolved the copper material, a state was eventually reached where only a thin layer of copper remained and the etch began to remove some of the rougher surface features originally created by the etch process. This effect was seen in the lower roughness values observed on the higher concentration $\mathrm{CuCl}_{2} / \mathrm{H}_{2} \mathrm{O}_{2} / \mathrm{HCl}$ etched samples. Removal of the copper traces down to the FR-4 substrate was a particular problem with the longer $120 \mathrm{~s}$ etch. Once the FR-4 was exposed, it became difficult to find continuous paths for measuring roughness. These trace breaks would also limit solder flow and cause electrical opens.

The roughness values of the $\mathrm{CuCl}_{2} / \mathrm{H}_{2} \mathrm{O}_{2} / \mathrm{HCl}$ etched samples were slightly lower than the $\mathrm{FeCl}_{3} / \mathrm{HCl}$ results, although the general etching trends were similar. The average roughness increase ranged between 0 and $50 \%$ of the baseline value. Once again, the lower concentration solution, at an etch time of $120 \mathrm{~s}$, yielded the roughest surface of 2.657 .

Three-dimensional images of the measured roughness data were plotted. Typical profiles and their peak-tovalley ranges are presented in Fig. 3 (a - baseline, b $\mathrm{FeCl}_{3} / \mathrm{HCl}$ at low concentration for $120 \mathrm{~s}$, and $\mathrm{c}$ - dual etch process). As observed with the measured roughness data, the baseline condition did exhibit a certain degree of roughness. The $\mathrm{FeCl}_{3}$ etch generally produced a relatively homogeneous surface topography with uniform, moderate scale peaks and valleys, as shown in Fig. 3-b. The $\mathrm{CuCl}_{2} / \mathrm{H}_{2} \mathrm{O}_{2} / \mathrm{HCl}$ etch yielded a more heterogeneous surface, with high peaks along the trace edges and deep, broad valleys over the remaining surface area. The dual etch process produced the most interesting results, 
yielding a bimodal topography consisting of generally uniform peaks and valleys with deeper interconnected grooves. This "grooved" topography is believed to be caused by preferential etching along the copper grain boundaries (Fig. 3-c) and is common to most chemical etching processes [19]. Under controlled conditions, the "grooved" pattern can enhance solder flow. If overetched, however, wider "grooves" with a shallow slope might inhibit flow.

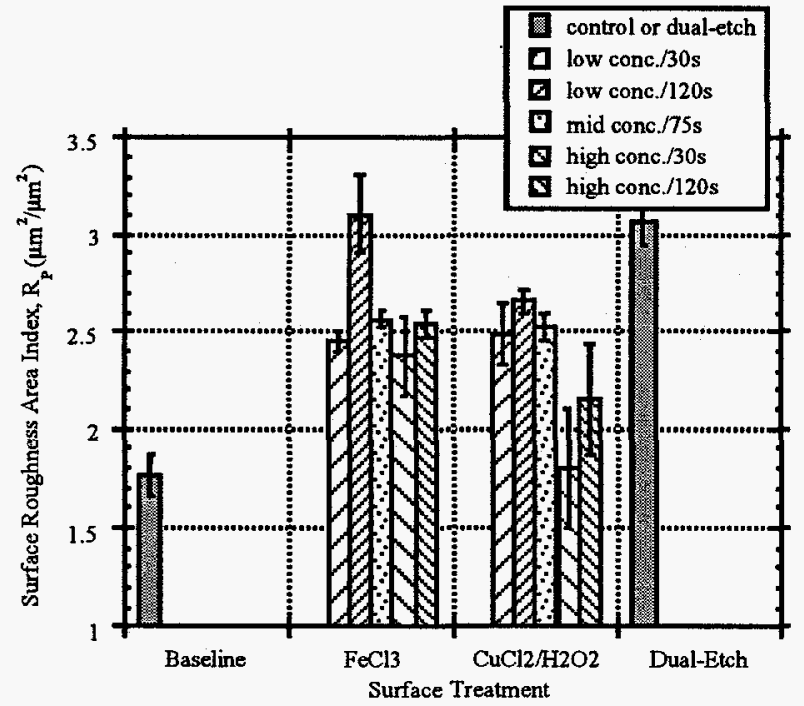

Figure 2: Surface roughness area index, $\mathbf{R}_{\mathbf{P}}$, on copper as a function of etch concentration and time $\left(R_{p}=1.0\right.$ is an ideal, smooth su rface).

To complete the surface analysis, etched substrates were cross-sectioned and mounted to measure the remaining copper thickness. Etch rates were then determined with the measured values and the given etch times. The $\mathrm{FeCl}_{3} / \mathrm{HCl}$ and dual etch conditions yielded a relative etch rate of $0.1 \mu \mathrm{m} / \mathrm{s}$. The higher concentration $\mathrm{FeCl}_{3} / \mathrm{HCl}$ chemistry was the exception, with an etch rate closer to $0.25 \mu \mathrm{m} / \mathrm{s}$. The higher etch rate resulted in excessive copper attack, especially at 120 s. The $\mathrm{CuCl}_{2} / \mathrm{H}_{2} \mathrm{O}_{2} / \mathrm{HCl}$ etch rate was less consistent and varied between 0.15 and $0.25 \mu \mathrm{m} / \mathrm{s}$, even across the same trace. As noted with the $\mathrm{FeCl}_{3} / \mathrm{HCl}$ etch, long etch times stripped most, if not all, of the copper features on the BGATVs, particularly with the higher etch concentration.

Solderability tests were conducted to characterize the solder flow behavior on the roughened surfaces. Wetting balance tests were performed with mixed results [11]. The wetting forces and times were generally good, but with minimal differences measured between the baseline and etched surfaces. A thin solder film in advance of the bulk solder was observed on the etched surfaces, however, and not on the baseline samples. This solder precursor is similar to the "precursor foot" phenomenon reported by other researchers [20-22] and is usually a good indicator of enhanced solder flow. The actual benefits of etching were likely underestimated, therefore, by the wetting

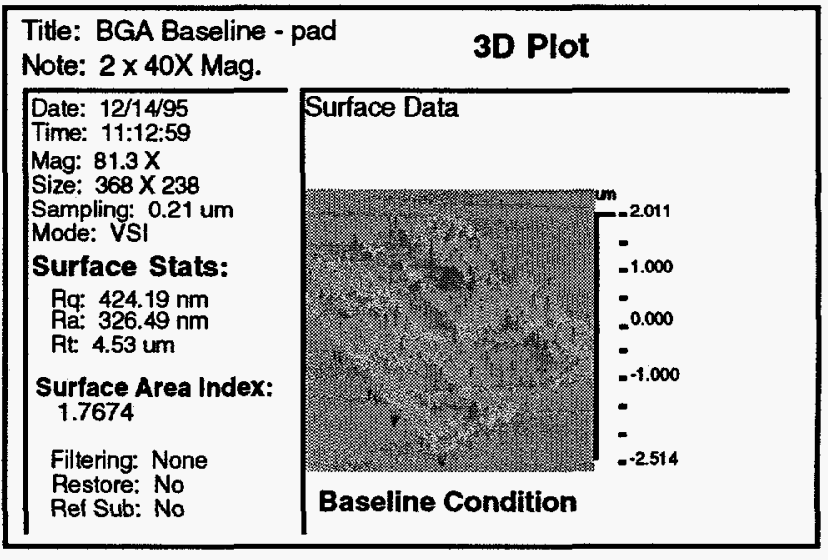

(a)

\begin{tabular}{|c|c|}
\hline $\begin{array}{l}\text { Title: BGA FH120 - line } \\
\text { Note: } 2 \text { × } 40 \times \text { Mag. }\end{array}$ & 3D Plot \\
\hline $\begin{array}{l}\text { Date: } 12 / 15 / 95 \\
\text { Time: } 13: 40: 17 \\
\text { Mag: } 81.3 \text { X } \\
\text { Size: } 368 \text { X238 } \\
\text { Sampling: 0.21 um } \\
\text { Mode: VSI } \\
\text { Surface Stats: } \\
\text { Rq: } 1.05 \mathrm{um} \\
\text { Ra: } 763.82 \mathrm{~nm} \\
\text { Rt: } 11.30 \mathrm{um}\end{array}$ & 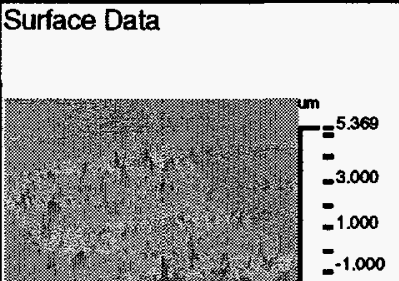 \\
\hline $\begin{array}{l}\text { Surface Area Index: } \\
3.077\end{array}$ & \begin{tabular}{l|l} 
& $=-3.000$ \\
- &
\end{tabular} \\
\hline $\begin{array}{l}\text { Filtering: None } \\
\text { Restore: No } \\
\text { Ref Sub: No }\end{array}$ & $\begin{array}{l}\mathrm{FeCl}_{3} \text { Etch (low conc } / 120 \mathrm{~s} \text { ) }\end{array}$ \\
\hline
\end{tabular}

(b)

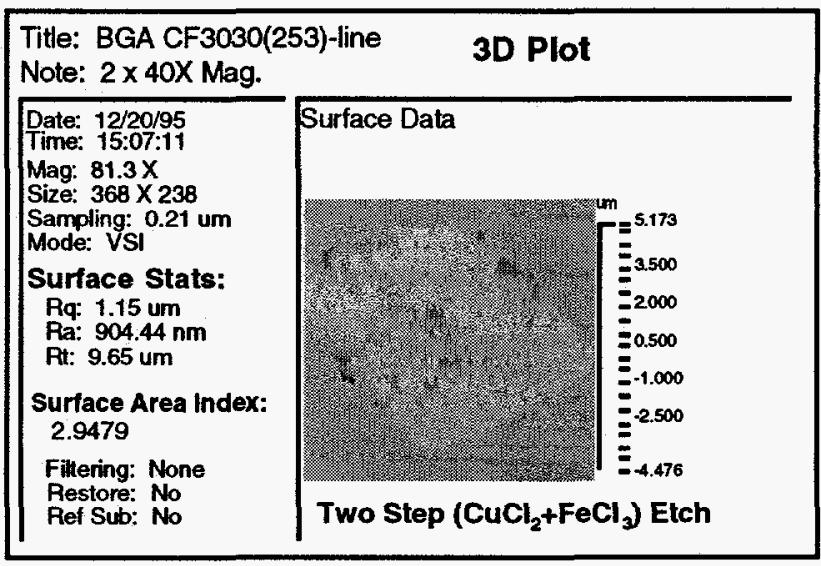

(c)

Figure 3: Mapped surface topography of (a) baseline, (b) $\mathrm{FeCl}_{3} / \mathrm{HCl}$ (low concentration, $120 \mathrm{~s}$ ), and (c) dual $\mathrm{CuCl}_{2} / \mathrm{H}_{2} \mathrm{O}_{2} / \mathrm{HCl}$ and $\mathrm{FeCl}_{3}$ etched BGATVs.

balance tests, due to the large surface area of the test coupon. The BGATV, on the other hand, provides a more sensitive means for capturing the response of flow to 
roughness. The BGATV tests discriminate solder flow from the pads, along the lines, and into the inner circuit array, a potential flow path of at least $7.5 \mathrm{~mm}$.

The results of the solder flow experiments are listed in Table 3 and displayed in Fig. 4. Flow was generally poor on the baseline BGATVs, with wetted lengths averaging less than $1.0 \mathrm{~mm}$. The $\mathrm{FeCl}_{3} / \mathrm{HCl}$ and $\mathrm{CuCl}_{2} / \mathrm{H}_{2} \mathrm{O}_{2} / \mathrm{HCl}$ etched samples clearly yielded better wetting results. The $\mathrm{FeCl}_{3} / \mathrm{HCl}$ etch produced more consistent solder flow under the given boundary condition chemistries and etch times, with wetted lengths of $4.0-5.0 \mathrm{~mm}$. It should be noted that solder tests were not conducted on the higher $\mathrm{FeCl}_{3}$ concentration, $120 \mathrm{~s}$ processed samples because of significant overetching and breaks in the copper lines. The solder results were consistent with the roughness and etch rate measurements reported above. Figure 5 shows a typical cross-section of a $\mathrm{FeCl}_{3} / \mathrm{HCl}$ etched and soldered sample, with its "rippled" solder/Cu interface.

Table 3: Etched BGATV Solder Flow Results

\section{Surface Treatment \& Time}

Baseline, $10 \% \mathrm{HCl}$

$\mathrm{FeCl}_{3}(127 \mathrm{~g})^{*}, 30 \mathrm{~s}$

$\mathrm{FeCl}_{3}(127 \mathrm{~g})^{*}, 120 \mathrm{~s}$

$\mathrm{FeCl}_{3}(253 \mathrm{~g})^{*}, 75 \mathrm{~s}$

$\mathrm{FeCl}_{3}(380 \mathrm{~g})^{*}, 30 \mathrm{~s}$

$\mathrm{FeCl}_{3}(380 \mathrm{~g})^{*}, 120 \mathrm{~s}$

$\mathrm{CuCl}_{2}(127 \mathrm{~g})+\mathrm{H}_{2} \mathrm{O}_{2}(7 \mathrm{ml})^{*}, 30 \mathrm{~s}$

$\mathrm{CuCl}_{2}(127 \mathrm{~g})+\mathrm{H}_{2} \mathrm{O}_{2}(7 \mathrm{ml})^{*}, 120 \mathrm{~s}$

$\mathrm{CuCl}_{2}(253 \mathrm{~g})+\mathrm{H}_{2} \mathrm{O}_{2}(14 \mathrm{ml})^{*}, 75 \mathrm{~s}$

$\mathrm{CuCl}_{2}(380 \mathrm{~g})+\mathrm{H}_{2} \mathrm{O}_{2}(21 \mathrm{ml})^{*}, 30 \mathrm{~s}$

$\mathrm{CuCl}_{2}(380 \mathrm{~g})+\mathrm{H}_{2} \mathrm{O}_{2}(21 \mathrm{ml})^{*}, 120 \mathrm{~s}$

$\mathrm{CuCl}_{2}(253 \mathrm{~g})+\mathrm{H}_{2} \mathrm{O}_{2}(14 \mathrm{ml})^{*}, 30 \mathrm{~s}$

followed by $\mathrm{FeCl}_{3}(253 \mathrm{~g})^{*}, 30 \mathrm{~s}$

* (per liter of 50 vol. \% HCl stock solution) the test pattern where flow exceeded this value and wet the inner circuit array.

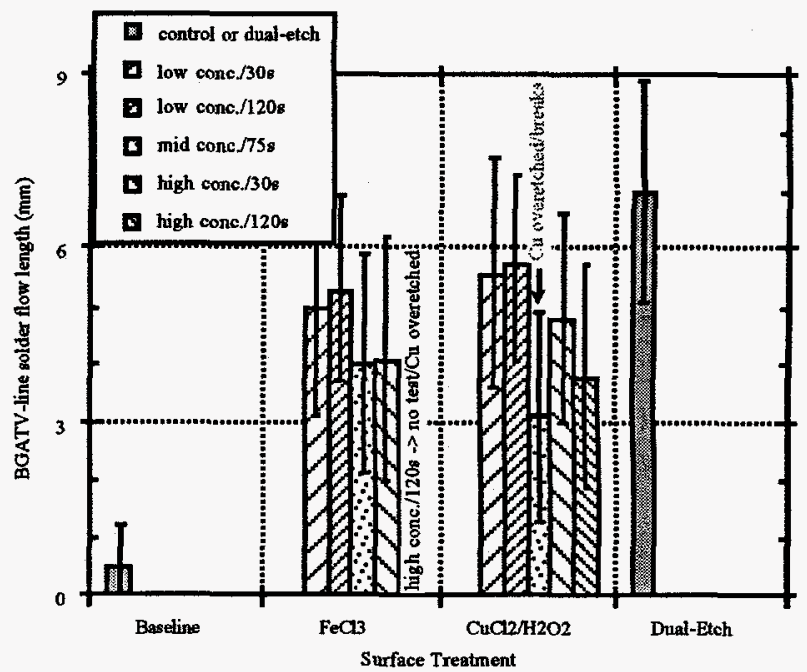

Figure 4: Solder flow on BGATV lines as a function of etch processing (i.e., surface roughness); error bars \pm one standard deviation.

This investigation clearly demonstrates the importance of roughness on solder wettability, regardless of the method used to create a distinctive surface topography. The desire for finer circuit features has made this issue particularly timely, as solder joint producibility and reliability requirements for advanced interconnects grow. Controlling the solder wetting and flow response, whether inhibited or enhanced, by engineering the physical properties of the surface should yield more robust fabrication and assembly processes.

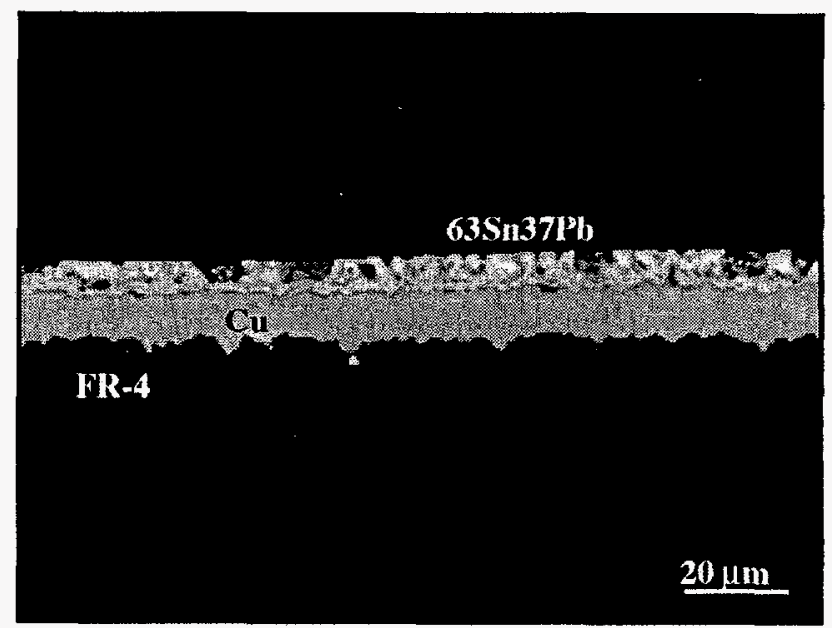

Figure 5: Optical image of a $\mathrm{FeCl}_{3} / \mathrm{HCl}$ etched and soldered BGATV line.

Another important outcome of the study was the

recognition of the significance of the baseline surface
The $\mathrm{CuCl}_{2} / \mathrm{H}_{2} \mathrm{O}_{2} / \mathrm{HCl}$ solution also gave good flow results, although the range of wetted lengths was typically greater, varying from 2.6 to $5.7 \mathrm{~mm}$. Some evidence of copper overetching was observed with increasing $\mathrm{CuCl}_{2} / \mathrm{H}_{2} \mathrm{O}_{2}$ concentration. $\mathrm{CuCl}_{2} / \mathrm{H}_{2} \mathrm{O}_{2}$ generally created wider "trenches" across the test lines which contributed to a more heterogeneous solder flow. A secondary problem was caused by $\mathrm{H}_{2} \mathrm{O}_{2}$ depletion in the etch bath, either through use or natural aging.

The dual $\mathrm{CuCl}_{2} / \mathrm{H}_{2} \mathrm{O}_{2} / \mathrm{HCl}$ and $\mathrm{FeCl}_{3} / \mathrm{HCl}$ etch process yielded the best wetting results. The process produced a uniform peak and valley topography, with additional deeper interconnected channels covering the surface, which further enhanced capillary flow. A low etch rate, with high roughness indicators, correlated into an average solder flow of $7.0 \mathrm{~mm}$. There were several longer lines on 
conditions prior to solder processing. For example, surface roughness is typically ignored as a process variable at the board level. This is usually not a problem with "older" PWB technology, since the surface area and processing window are larger. With more advanced technology, however, the materials and processing limits have shrunk and are less forgiving. As a consequence, the roughness parameter can no longer be treated as a constant. Chemical etching may not be the best way for producing the desired roughness features because of its subtractive nature and the difficulties associated with its incorporation into an existing production line. The essential point, however, is to clearly understand the significant effect that roughness can have on fabrication and assembly level defects.

\section{CONCLUSIONS}

Microscopically roughened PWB copper surfaces were produced with different chemical solutions. The solutions were based on $\mathrm{FeCl}_{3} / \mathrm{HCl}$ and $\mathrm{CuCl}_{2} / \mathrm{H}_{2} \mathrm{O}_{2} / \mathrm{HCl}$ chemistries. The effects of etch concentration and etch time on surface roughness and solder flow were determined. The $\mathrm{FeCl}_{3} / \mathrm{HCl}$ solutions generally yielded a more uniform etched surface than the $\mathrm{CuCl}_{2} / \mathrm{H}_{2} \mathrm{O}_{2} / \mathrm{HCl}$ etchants. Overall, solder wetting and flow were improved when compared to the baseline control condition, especially at the lower etch concentrations. A sequential process, using $\mathrm{CuCl}_{2} / \mathrm{H}_{2} \mathrm{O}_{2}$ and $\mathrm{FeCl}_{3}$, was particularly effective in achieving enhanced solder flow along the very fine test lines. The results clearly demonstrated the importance of surface roughness on solder flow, whether produced by chemical or mechanical means. Not understanding or controlling this surface property could lead to serious problems during fine line fabrication and assembly processing.

\section{ACKNOWLEDGMENTS}

The authors wish to thank Darrel Frear for his review of the manuscript. The authors also acknowledge Fred Yost for technical insight into surface science fundamentals and Alice Kilgo for metallographic support. Technical comments from the NCMS PWB Surface Finishes Team were also valuable. The work was performed under CRADA No. 01030B and supported by the U.S. Department of Energy's Defense Programs, Technology Transfer Initiative.

\section{REFERENCES}

[1] R. N. Wenzel, Ind Eng Chem, 28, 988 (1936).

[2] E. R. Parker and R. Smoluchowski, Trans. ASM 35,362 (1944).

[3] R. Shuttleworth and G. L. J. Bailey, Disc. Earaday Soc. 3, 16 (1948).

[4] R. E. Johnson and R. H. Dettre, Contact Angle. Wettability and Adhesion (edited by R. F. Gould). Advances in Chemistry Series 43, American Chemical Society (1964).

[5] S. J. Hitchcock, N. T. Carroll, and M. G. Nicholas, J. Mater. Sci., 16, 714 (1981).

[6] M. G. Nicholas and R. M. Crispin, J. Mater. Sci., 21, 522 (1986).
[7] A. M. Cazabat and M. A. Cohen Stuart, L Phys. Chem., 90, 5845 (1986).

[8] L. Romero and F. G. Yost, "Flow in an OpenChannel Capillary", L. Fluid Mech, accepted for publication.

[9] F. G. Yost, J. R. Michael, and E. T. Eisenmann, "Extensive Wetting due to Roughness", Acta Metall. Mater. 43, 299 (1995).

[10] D. M. Tench and D. P. Anderson, "Uniform Solder Coating on Roughened Substrate", Rockwell International Corp., US Patent 5178965 (1993).

[11] J. O. Stevenson, T. R. Guilinger, F. M. Hosking, F. G. Yost, and N. R. Sorensen, "Solderability Enhancement of Copper Through Chemical Etching", IPC Expe '95 Conf. Proceedings. San Diego, CA, (May 1995).

[12] F. M. Hosking, J. O. Stevenson, and F. G. Yost, "Capillary Flow of Solder on Chemically Roughened PWB Surfaces", IPC '96 Conf. Procs, San Jose, CA, S6-3/1-5 (March 1996).

[13] E. Kauczor, "Preparation of Test Pieces for Macroscopic Examination", Praktiker, 30 (5), 82-84 (May 1978).

[14] "Metallography and Microstructures", ASM Handbook, Vol. 9, ASM International (1985).

[15] "Surface Engineering", ASM Handbook, Vol. 5, ASM International (1994).

[16] J. Chiang, "Process of Etching Copper Circuits", FMC Corp., US Patent 3844857 and US Patent 3837945 (1974).

[17] ASME 846.1 85, American Society of Mechanical Engineers (1992).

[18] F. M. Hosking, and F. G. Yost., "Characterization of Solder Flow on PWB Surfaces", Surface Mount International Conference Proceedings, 545-550 (August 1995).

[19] V. E. Fradkov, Scripta Metall et Mat, 30 (12), 1599-1603 (1994).

[20] A. Bondi, Chem, Rey, 52, 417 (1953).

[21] G. C. Smith and C. Lea, Surf. Inter. Analy., 9, 145 (1986).

[22] T. J. Singler, J. A. Clum, and E. R. Prack, Trans. ASME, 114, 128 (1992). 